\title{
Pure cystic groove pancreatitis: endosonographic appearance
}

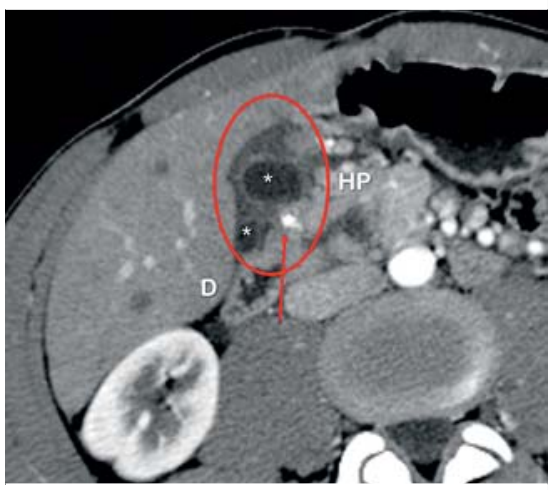

- Fig. 1 Contrast-enhanced computed tomography scan showing an inhomogeneous hypodense area (circled in red) containing some well-delineated and rounded cysts $\left({ }^{*}\right)$ with millimetric calcifications (arrow) between the head of the pancreas (HP) and the first part of the duodenum (D).

A 24-year-old man, who was an active smoker (20 cigarettes per day) since the age of 7 years and had a history of chronic alcohol abuse, was referred to our hospital because of recurrent mild-severe abdominal pain localized in the upper quadrants and sometimes radiating to the back. In 2012 he was hospitalized for an episode of alcoholic mild-acute pancreatitis. He then stopped drinking alcohol for 3 years, with clinical and nutritional benefits. In 2015 he began abusing alcohol again, and the abdominal pain recurred together, with progressive weight loss.

Because of the persistence of symptoms, biochemical blood tests were performed and showed a mild increase in gammaglutamyl transferase $(2 \times$ the upper limit of normal [ULN]), amylase/lipase (2.5/ $1.5 \times$ ULN), and carbohydrate antigen 19-9 ( $2 \times$ ULN). A computed tomography scan showed the presence of a hypodense area between the head of the pancreas and the duodenal wall, which contained some cysts associated with millimetric calcifications ( $>$ Fig. 1). A magnetic resonance imaging (MRI) scan confirmed an isointense area containing multiple small
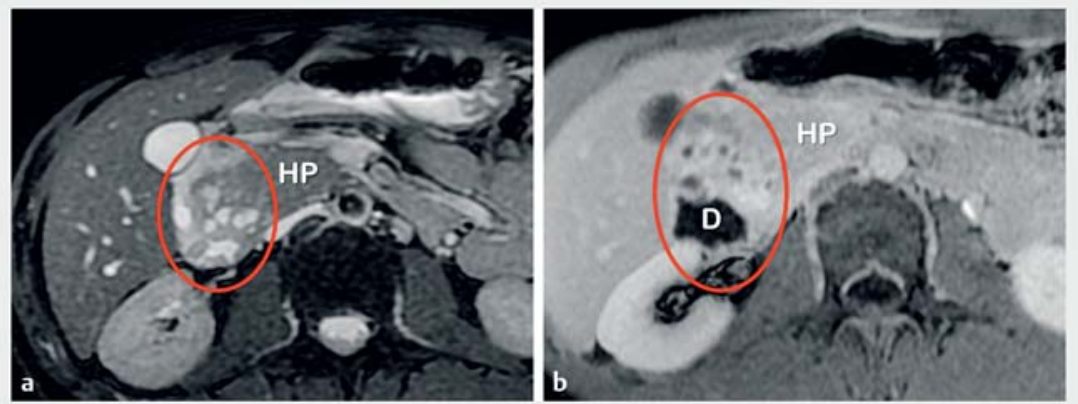

- Fig. 2 Magnetic resonance imaging showing an inhomogeneous isointense area containing small multiple cysts (circled in red) between the head of the pancreas (HP) and the first part of the duodenum (D). a T2-weighted FIESTA image; b T1-weighted contrast-enhanced image.
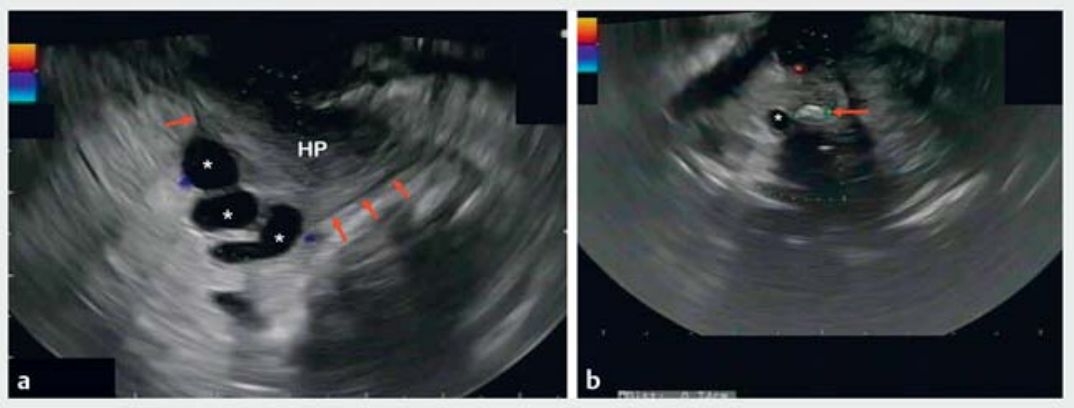

- Fig. 3 Linear-array endoscopic ultrasound view of the groove area from the second portion of the duodenum. a Multiple cystic lesions $\left({ }^{*}\right)$ involving the muscularis propria of the duodenal wall (arrows) next to the head of the pancreas (HP), which presents regular echogenicity. $\mathbf{b}$ Small calcification (arrow) next to one of the cysts $\left({ }^{*}\right)$.

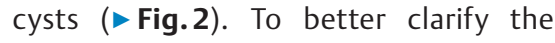
nature of these findings, we performed an endoscopic ultrasound (EUS), which showed an inhomogeneous area between the head of the pancreas, the duodenum, and the common bile duct, with multiple small anechoic lesions and millimetric calcifications ( $>$ Fig. 3 , \ Video 1 ). These findings, together with clinical and anamnestic data, are consistent with a diagnosis of the cystic variant of puretype groove pancreatitis [1], a rare form of chronic pancreatitis also known as cystic dystrophy of the heterotopic pancreas, paraduodenal wall cyst, myoadenomatosis, or paraduodenal pancreatitis
[2]. EUS is now considered an important tool, together with MRI, for a diagnosis of groove pancreatitis [3-5]. However, EUS morphologic features of groove pancreatitis have not been extensively reported to date.

Endoscopy_UCTN_Code_CCL_1AZ_2AL 


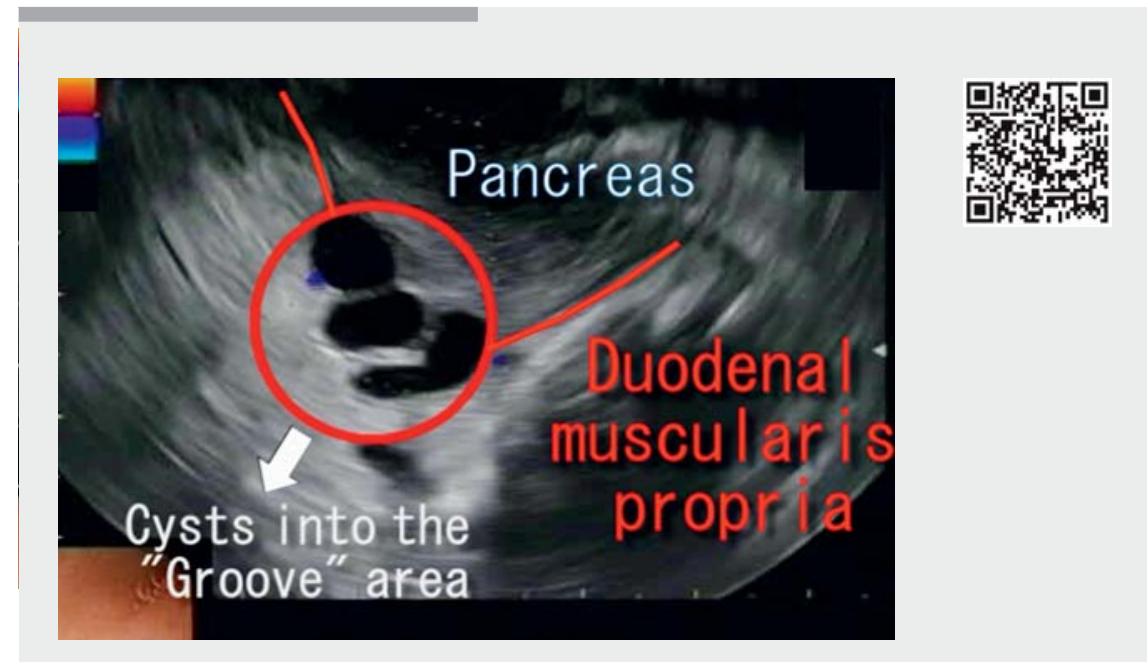

Video 1 Endoscopic ultrasound view of a pure-type cystic variant of groove pancreatitis.

\section{Competing interests}

None

The authors

Dario Ligresti ${ }^{1}$, Matteo Tacelli ${ }^{2}$, Michele Amata ${ }^{1}$, Luca Barresi ${ }^{1}$, Settimo Caruso ${ }^{3}$, Ilaria Tarantino ${ }^{1}$, Mario Traina ${ }^{1}$

1 Endoscopy Service, Department of Diagnostic and Therapeutic Services, IRCCSISMETT (Istituto Mediterraneo per i Trapianti e Terapie ad alta specializzazione), Palermo, Italy

2 Section of Gastroenterology, Biomedical Department of Internal and Specialized Medicine (DI.BI.M.I.S.), University of Palermo, Palermo, Italy

3 Radiology Unit, Department of Diagnostic and Therapeutic Services, IRCCS-ISMETT (Istituto Mediterraneo per i Trapianti e Terapie ad alta specializzazione), Palermo, Italy
Corresponding author

\section{Dario Ligresti, MD}

Endoscopy Service, Department of Diagnostic and Therapeutic Services, IRCCS ISMETT - UPMC, Via E. Tricomi 5, 90127

Palermo, Italy

Fax: +39-091-2192400

dligresti@ismett.edu

\section{References}

[1] Becker V, Mischke U. Groove pancreatitis Int J Pancreatol 1991; 10: 173-182

[2] Adsay NV, Zamboni G. Paraduodenal pancreatitis: a clinico-pathologically distinct entity unifying "cystic dystrophy of heterotopic pancreas," "para-duodenal wall cyst," and "groove pancreatitis". Semin Diagn Pathol 2004; 21: 247-254

[3] Casetti L, Bassi C, Salvia R et al. "Paraduodenal" pancreatitis: results of surgery on 58 consecutives patients from a single institution. World J Surg 2009; 33: $2664-2669$
[4] Jun JH, Lee SK, Kim SY et al. Comparison between groove carcinoma and groove pancreatitis. Pancreatology 2018; 18: 805-811

[5] Levenick JM, Gordon SR, Sutton JE et al. A comprehensive, case-based review of groove pancreatitis. Pancreas 2009; 38: e169-175

\section{Bibliography}

DOI https://doi.org/10.1055/a-0889-7569

Published online: 2.5.2019

Endoscopy 2019; 51: E235-E236

(c) Georg Thieme Verlag KG

Stuttgart · New York

ISSN 0013-726X

\section{ENDOSCOPY E-VIDEOS}

https://eref.thieme.de/e-videos

回的回 Endoscopy E-Videos is a free access online section, reporting If: on interesting cases and new techniques in gastroenterological endoscopy. All papers include a high quality video and all contributions are freely accessible online.

This section has its own submission website at

https://mc.manuscriptcentral.com/e-videos

\section{CORRECTION}

Pure cystic groove pancreatitis: endosonographic appearance Ligresti D, Tacelli M, Amata M et al. Pure cystic groove pancreatitis: endosonographic appearance. Endoscopy 51, 2019: E235-E236 In the above-mentioned article the institution affiliation of Settimo Caruso has been corrected.

This was corrected in the online version on February 28, 2020. 